\title{
The effects of introducing electric adjustable height desks in an office setting on workplace physical activity levels: A randomised control field trial
}

\author{
Jane Pierce ${ }^{\mathrm{a}, *}$, Stephen Legg ${ }^{\mathrm{a}}$, Jonathan R. Godfrey ${ }^{\mathrm{b}}$ and Emily Kawabata ${ }^{\mathrm{b}}$ \\ ${ }^{a}$ Centre for Ergonomics Occupational Safety and Health, School of Public Health, College of Health, \\ Massey University, Palmerston North, New Zealand \\ ${ }^{\mathrm{b}}$ Statistics and Bioinformatics Group, Institute of Fundamental Sciences, Massey University, Palmerston North, \\ New Zealand
}

Received 23 July 2017

Accepted 16 April 2018

\begin{abstract}
.
BACKGROUND: Electric adjustable height desks (EAHD) have been promoted as an opportunity for desk based workers to stand at work but there is limited evidence that they have an effect on light physical activity.

OBJECTIVE: The main objective was to determine if there would be a change in light physical activity with the introduction of EAHD. The secondary objective was to assess if there was an associated change in leisure time activity.

METHODS: Activity levels were measured by step counts, self-reported activity levels and pre- and post-trial recall levels. Statistical analysis of the data was performed with the software R. Generalised linear models were fitted to the data. A Poisson regression was used for count data. Statistical hypotheses were deemed significant if their $p$ values were less than 0.05 .

RESULTS: There was a significant $(p<0.001)$ effect on step counts associated with allocation of EAHD and a significant $(p<0.001)$ increase in self-reported activity for the Intervention (EAHD) group. Having an EAHD was associated with increased activity during leisure $(p=0.039)$.

CONCLUSIONS: Activity levels, especially light physical activity, were significantly increased with the allocation of an electric adjustable height desk. This pilot study showed that the environmental change of introduction of electric adjustable height desks into an office workplace can increase physical activity and reduce sitting durations. There is limited evidence that the increase in work activity has a positive impact on leisure time activity.
\end{abstract}

Keywords: Sitting, standing, work, workstations, physical ergonomics, sit/stand

\section{Introduction}

Prolonged static postures have been recognised as a contributor to musculoskeletal discomfort (MSD) since Ramazzini's recorded observations in the 17th

\footnotetext{
*Address for correspondence: Jane Pierce, Centre for Ergonomics Occupational Safety and Health, School of Public Health College of Health, Private Bag 11222. Massey University, Palmerston North, New Zealand. Tel.: +64 6876 9838; E-mail: workcatalyst@gmail.com.
}

Century [1]. The human body requires movement both to nourish structures by increasing blood flow and to provide periodic rest for muscles to prevent fatigue [2]. Standing could form a basis for musculoskeletal injury prevention for seated desk-based workers [2]. With the advancement of mechanisation and expansion of computerisation more workers are engaged in desk-based occupations and are becoming increasingly sedentary [3-5]. For example, in approximately 15 hours of a waking day for a working 
population $[6,7]$, more than half is spent sedentary [8]. Since work time accounts for almost half of the daily total [9-12] the workplace has been identified as an opportunity for reducing overall sedentary time and for introducing physical activity.

Sedentary occupations have been recognised as a health risk as long ago as 1958, when Morris et al. [13] showed a link between heart disease and reduced physical activity at work. More recent research has reported that sedentary behaviour may be linked to an increased risk of detrimental health effects such as diabetes, cardiovascular disease and possibly cancer [8,14-19]. Sedentary behaviour is defined as any waking behaviours that are done sitting or reclining and cost $\leq 1.5$ times the basal metabolic rate [20]. Current recommendations [19, 21, 22], point to increasing the number of breaks in sedentary time as well as decreasing overall sedentary time. Adjustable height desks (AHD) have been promoted as an environmental intervention to reduce workplace sitting by allowing the worker to switch between sitting and standing whilst engaged in work [19, 23, 24].

There is a growing body of evidence to support the beneficial effects of the use of AHDs at work. However, there are gaps in the literature. Only a few studies have been long term (over seven weeks) [5, 22, 25-28] allowing for evaluation of continued and sustainable change at work. Several studies have been part of workplace health promotions to reduce occupational sitting ((Stand Up Australia series 2009, 2011, 2012 [28-30]; Stand up Victoria 2013 [31]; Stand @Work Study 2012 [32, 33]; Stand Up Sit Less Move More [28, 34]; the North American Take A Stand Project 2011 [25]) or involved staff who would have had prior knowledge of the detrimental effects of workplace sitting [25, 26, 32, 33]. A number of studies used desk mounted workstations, not desks, to facilitate standing at work [22, 25, 26, 28, 32-36]. Other studies had different styles and types of AHDs, including electrical and mechanical adjustments in their studies [37-39] so there is lack of homogeneity of desk types in the studies.

Although the outcomes of research consistently demonstrate a reduction of sitting time in office settings with AHD, there appears to be a lack of consensus in the literature on changes to sitting and standing times. In a review of fourteen studies on AHDs prior to 2009, Karakolis et al. [40] reported that the ratio of standing to sitting varied amongst the studies. Increases in time spent standing to between $21 \%$ and $23 \%$ of the work day with the introduction of AHD have been reported [36-38, 41, 42]. However, in an observational study of office and leisure activity, Thorp et al. [29] reported $77 \%$ of working hours were sedentary, which left up to $23 \%$ of work time not sitting, without any intervention. Tobin et al. [36] reported the same measurements as Thorp et al. [29] at baseline before the introduction of an adjustable workstation. Ryan et al. [43] measured sitting patterns at work and reported a mean of $66 \%$ (SD 12\%) of the working day was spent sitting. Straker et al. [39] found that $21.5 \%$ of the day was standing with a sit-stand desk compared to $16.2 \%$ of the day with a conventional fixed sitting height desk. Using an accelerometer van Dommelen [12] recorded white collar workers sitting for between $76-80 \%$ of their occupational time. The results from these studies [12, $29,36]$ support the baseline of normal sitting and standing patterns at work.

Studies on sedentary behaviour at work have mainly used a dichotomous measurement of either sitting or standing. Messing et al. [44] have cautioned on the emphasis on standing as a measure of success for studies reducing sedentary behaviour due to the adverse health effects of prolonged standing. Physical inactivity $[1,45]$ and lack of decision latitude to change postures is associated with increased MSD and adverse health effects [46]. Prior to this study there was a lack of research on changes of light physical activity with the introduction of AHD, however recent studies $[30,35,36]$ have examined the effects on light physical activity and stepping. While acknowledging the benefits of moderate to vigorous physical activity, an increase in incidental movement has the potential to have positive health benefits $[8$, 21, 47].

Previous research on physical activity has identified a complex relationship between activity levels in the domains of work and leisure. People in active occupations were likely to be engaged in less leisure activity [48] but still meet daily activity requirements. McCrady et al. [49] found work days being associated with more sitting, and noted personal traits could be a predictor of activity levels. Workers engaged in sedentary occupations may not compensate with higher leisure time activity $[35,50]$. The increasing sedentariness of workplaces has been identified as a factor in reducing overall activity levels [11] and workplaces have therefore been focus of attention for physical activity programmes. However, there is limited evidence that workplace physical activity promotion has shown an increase in leisure activity [51].

In summary, the gaps in the literature have been identified as: few long term studies in a natural 
office setting with electric adjustable height desks (EAHD) using randomised control subjects; no studies to assess changes in light physical activity with the allocation of an EAHD in an office workplace setting where participants are allowed to change their postures as they choose. In addition, to date there have been few studies on whether increasing activity at work with the allocation of an EAHD would have any effect on leisure time activity.

The primary aim of this study was to determine if the allocation of EAHDs in a real world office setting would influence activity during work hours by increasing light physical activity and reducing sitting. The only intervention was the allocation of EAHDs. A secondary aim was to determine if the allocation of an EAHD had any effect on leisure time activity levels.

\section{Methods}

\subsection{Study design}

The study was a randomised controlled field trial of the introduction and use of EAHDs in a branch of a medium sized energy company in Hastings, New Zealand. The company has approximately 170 staff with $60 \%$ male and $40 \%$ female staff. Before the start of the study, all study participants used traditional fixed sitting height desks (FSHDs) and had been given a workstation assessment by a physiotherapist as a standard part of their initial company orientation.

The company requested the project before they committed to purchasing further desks as at that time there was scant evidence to support the benefits of the use of EAHD in workplaces.

The study was approved as a Low Risk Notification by Massey University Human Ethics Committee.

\subsection{Participants and adjustable height desks}

All staff were invited to express their interest in participating via the company intranet. Twenty seven responded. Twenty four (12 female; 12 male) met the inclusion criteria (greater than 0.8 Full Time Equivalent, ambulatory with no history of significant illness or injury) and were selected to participate. They all provided prior written informed consent. None were current smokers. Eight reported no previous or current musculoskeletal discomfort. Sixteen reported occasional back or shoulder discomfort. None had previously used an AHD. They were all either pro-
Table 1

Participant demographics

\begin{tabular}{lccc}
\hline & $\begin{array}{c}\text { All } \\
(n=24)\end{array}$ & $\begin{array}{c}\text { Intervention } \\
(n=12)\end{array}$ & $\begin{array}{c}\text { Control } \\
(n=11)^{*}\end{array}$ \\
\hline Age [years] & $39[9.5]$ & $39.8[10]$ & $39.6[9.4]$ \\
& (range 22 to 58) & $(28$ to 58) & $(22$ to 49) \\
Gender & 11 male; & 5 male; & 6 male; \\
& 12 female & 7 female & 5 female \\
BMI & $28.5[6]$ & $26.8[3.7]$ & $30.4[7.5]$ \\
& (range 20.2 & (range 21.5 & (range 20.2 \\
& to 46.3) & to 32.8) & to 46.3) \\
\hline
\end{tabular}

Age and BMI presented as mean [and standard deviation] *one participant withdrew due to injury.

fessional or administrative staff and most of their work was computer based, spending at least $80 \%$ of their work time at their workstation. Their other work activities were reading, telephone contacts, spreadsheets, design and office based or off-site meetings.

The participants were randomly divided into two groups of twelve by self selection of coded envelopes-an Intervention group who were allocated EAHDs (Espace Blake electronically height adjustable workstation $2000 \times 1200 \times 700 \mathrm{~mm}$ with left or right hand returns) and a Control group who retained their FSHDs. The Intervention group comprised seven females and five males. The Control group comprised five females and six males (one male withdrew due to a non-work-related injury) (Table 1).

All of the EADHs were installed on the same day by the same technician and participants were given instruction on the adjustable height functions. Within a week of EAHD installation each member of the Intervention group was given a workstation assessment by a physiotherapist for standing desk use by the first author (JP). The Control group were not given information on standing desks. None of the participants were given any information about current research findings on the effects on health of prolonged sitting or the potential role of AHDs.

\subsection{Data collection}

The study was run from July to October 2013. Prior to the start of the study all participants were allocated individual pedometers and physical activity diaries (PADs). They were fully briefed on how and when to use them. Pedometer and PADs data were collected on one working day at fortnightly intervals over 16 weeks. Eight separate days of data were collected for all participants, the first two days of data were collected at baseline and just prior to the installation of the desks at the beginning of week three, 
and subsequently data was collected at fortnightly intervals on six additional days for both groups. In addition, a pre- and post-study questionnaire was completed by all participants at baseline and after the study. In summary, physical activity was assessed by step counts, self-reported activity on PADs and comparison between pre- and post-trial questionnaires. Leisure activity and tiredness were measured by preand post-study questionnaires.

\subsection{Step counts}

Step counts were self-recorded by all participants on their PADs for the time they were at the workplace on the data collection days. A total work day count was recorded. Average step counts were calculated for each participant from their recorded steps. Daily averages for each group were calculated for the data collection days. Both the Intervention and the Control groups had two averages calculated-the first was for the period prior to EAHD being allocated (i.e. two collection days) and the second was after EAHDs were allocated (i.e. six collection days).

\subsubsection{Pedometers}

Pedometers (Keep Walking-Stay Fit, made in China) supplied by the workplace were used to record daily readings of step counts. They were individually pre-calibrated by the first author (JP) on a $100 \mathrm{~m}$ track and found to vary by up to 4 steps for repeated trials.

Pedometers were chosen as they are an objective low cost measure of ambulatory data. They have been shown to relate positively to self-reports of physical activity [52].

\subsection{Physical activity}

Physical activity data was collected by individual step counts on one day per fortnight as well as selfreported activity levels on the same day. In addition, individual physical activity was self-assessed in the pre and post-study questionnaires.

\subsubsection{Physical activity diaries}

On one day per fortnight all participants completed the self-report PAD to record the predominant activity for the preceding 15 minutes in the following categories: sitting; standing still; standing and moving less than $1.5 \mathrm{~m}$; and standing and moving more than $1.5 \mathrm{~m}$. This provided an indication of level of activity. Desk height was also recorded by the Intervention group at 15 minute intervals for two levels-high or low. This was used for verification of the reported activity. The Control group did not have to record desk height as their desks heights were constant. Prior to each data collection day the participants were sent an email reminder. The PADs were submitted on paper or electronically. From the PADs frequency count data was obtained for each of the activity levels: sit: standing still; standing and moving less than $1.5 \mathrm{~m}$; standing and moving more than $1.5 \mathrm{~m}$.

The PADs are time use diaries used to record office task and posture/activity for the time participants spent at their desk during the work day, at 15 minute intervals. Laperrière et al. [53] used a similar measure as a self-report of movement for their study on validity of questions on working posture.

\subsubsection{Pre and post-study questionnaire}

Pre- and post-study questionnaires were used to obtain self-reports on activity levels and tiredness after work. The pre-study questionnaire was administered at baseline during the information meeting prior to the participant's awareness of their allocation to Control or Intervention group. The post-study questionnaire was administered at a meeting at the end of the 16 week data collection period. In the questionnaire, participants were asked to rate their work postures (sitting, standing, walking) and 'tiredness after work' on a five point Likert scale (never; seldom; sometimes; often; always) over the previous month. They were also asked to rate their 'physical activity during leisure time against others of the same age', with a five point Likert scale of response categories (much more, more, same; less, much less).

Questions for activity and tiredness were taken from the Baecke questionnaire for habitual physical activity [54]. The Baecke Questionnaire measures occupational and leisure physical activity as well as locomotion activities in a five point scale. Although there have been several studies [55] testing the validation and reliability of the full questionnaire, the reliability and validity for a shortened questionnaire has not been assessed. The Questionnaire has not previously been used for pre and post intervention studies.

\subsection{Statistical analysis}

The impact of group (Intervention or Control), gender, activity type, pre-/post-desk allocation and week were analysed using R3.1.2 (R Core Team, 2014). A generalised linear model with a log link function was used for all response variables that were counts. 
Statistical hypotheses were deemed significant if $p$ values were less than 0.05 .

Frequency counts of the four activities were analysed with the other variables of Group (Intervention or Control), Gender, Week and Individual using a Fisher's Exact Test, which was used because of the small sample size. Mean counts were examined and proportions were calculated for Group (Intervention or Control) and Gender for each week. With respect to the analysis of pre- and post- questionnaires, each activity was analysed using a Fisher's Exact Test. A change in perspective variable was created for each individual: a positive value for an increase between the pre-study and post-study reported activity; a negative value for a decrease; and a zero value indicated no change between the pre- and post-study self-reports of activity.

Fisher's Exact Test was also used for Tiredness after Work and Leisure activity. As Gender was found to be significant, a Fisher's Exact Test was done for Gender and Leisure. $P$-values were calculated for the Fisher's Exact Tests.

\section{Results}

The use of EAHD was significantly associated with increases in workplace activity for pedometer step counts, light intensity activity during work and reported activity levels from the post-study recall questionnaires. The Intervention group also reported significantly increased levels of leisure time physical activity in the post-study questionnaire. Although the sample size was small there were differences in pattern of movement for gender for activity levels at work and reports of leisure activity. Specific detailed findings are given below.

\subsection{Step counts}

Overall there was a significant $(p<0.001)$ effect on step counts associated with allocation of EAHD (Fig. 1) with increase of daily step counts for the Intervention group. However, this difference depends on the individual's gender $(p<0.001)$ There were individual differences in step counts for all participants [range 170 to 18154 steps per day], independent of having an EAHD. Females had higher step counts than males. Step count data for the Intervention group had two peaks, at initial allocation of the AHD and again at data collection weeks five and six of the intervention. The Control group also demonstrated an increase in weeks five and six. The step count levels stabilised by the end of the trial.

\subsection{Activity at work}

\subsubsection{Data from physical activity diaries}

There was a significant $(p<0.001)$ increase in selfreported activity for the Intervention (EAHD) group

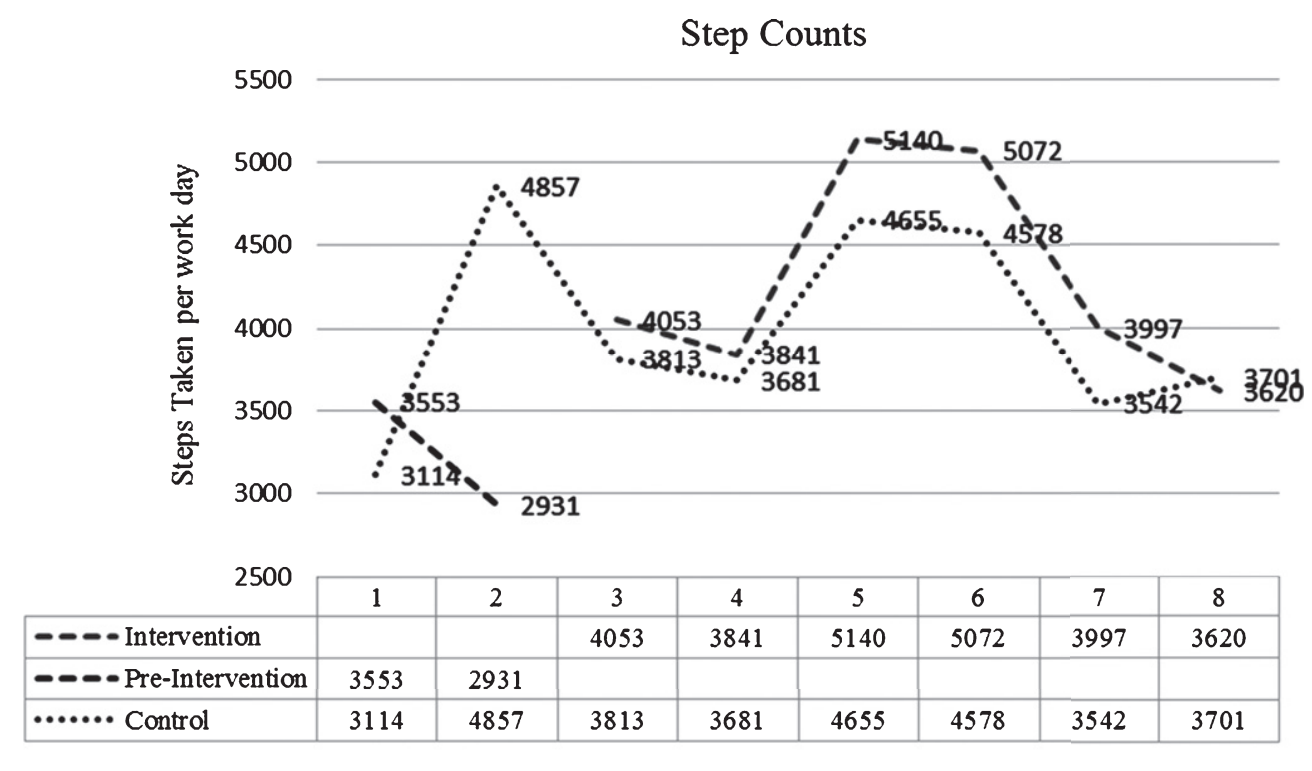

Weeks 1-2 pre intervention; 3-8 post intervention

Fig. 1. Step counts for Intervention group pre and post allocation of EAHD and Control group for all of study period. 
Table 2

Proportion of the work day in different activity levels for Intervention and Control groups

\begin{tabular}{|c|c|c|c|c|}
\hline $\begin{array}{l}\text { Activity } \\
\text { Level }\end{array}$ & $\begin{array}{c}\text { Intervention } \\
\text { Male }\end{array}$ & $\begin{array}{c}\text { Intervention } \\
\text { Female }\end{array}$ & $\begin{array}{c}\text { Control } \\
\text { Male }\end{array}$ & $\begin{array}{l}\text { Control } \\
\text { Female }\end{array}$ \\
\hline \multicolumn{5}{|l|}{ Walk $>1.5 \mathrm{~m}$} \\
\hline Weeks $1-2^{\#}$ & $26 \%$ & $27 \%$ & $15 \%$ & $20 \%$ \\
\hline Weeks $3-8^{\wedge}$ & $35 \% * * *$ & $28 \%$ & $14 \%$ & $19 \%$ \\
\hline \multicolumn{5}{|l|}{ Walk $<1.5 \mathrm{~m}$} \\
\hline Weeks $1-2^{\#}$ & $14 \%$ & $5 \%$ & $8 \%$ & $6 \%$ \\
\hline Weeks $3-8^{\wedge}$ & $15 \%$ & $28 \%$ *** & $6 \%$ & $3 \%$ \\
\hline \multicolumn{5}{|l|}{ Stand } \\
\hline Weeks $1-2^{\#}$ & $1 \%$ & $1 \%$ & 0 & $2 \%$ \\
\hline Weeks $3-8^{\wedge}$ & $32 \% * * *$ & $14 \%$ *** & $<1 \%$ & $<1 \%$ \\
\hline \multicolumn{5}{|l|}{ Sit } \\
\hline Weeks $1-2^{\#}$ & $59 \%$ & $67 \%$ & $77 \%$ & $72 \%$ \\
\hline Weeks $3-8^{\wedge}$ & $17 \%$ & $30 \%$ & $80 \%$ & $77 \%$ \\
\hline
\end{tabular}

Due to rounding of numbers some totals exceed $100 \%$; ${ }^{\#}$ Weeks 1-2: all participants used FHSD; ${ }^{\wedge}$ Weeks 3-8: Intervention group had EAHD; ${ }^{* * *}$ indicates a significant difference at $p<0.001$.

from the fortnightly PADs, with significant increases in standing still $(p<0.001)$, standing and moving less than 1.5 metres $(p<0.001)$ for females and standing and moving more than 1.5 metres $(p<0.001)$ for males. Females who were allocated an EAHD reported less standing still $(p<0.001)$ than males and more standing and moving less than 1.5 metres. Females allocated an EAHD did not exhibit change in their levels of standing and moving $>1.5$ metres but increased their activity $<1.5$ metres whereas males demonstrated an opposite effect by increasing their activity $>1.5$ metres and maintaining their activity $<1.5$ metres (Table 2).

Individuals in the Intervention group showed greater week by week variation in their reported activity levels than the Control group.

\subsubsection{Data from pre and post study questionnaires}

Perceived changes in activity levels from the pre- and post-questionnaires showed significant $(p=0.038)$ interaction for the Intervention group with EAHD and physical activity compared to the Control group. Gender was found not to be significant for this analysis and is not presented.

From the pre- and post-questionnaires the Intervention group reported an increased frequency for both moving and standing. However, there was still a 50\% reported rate of 'often' for sitting, showing that there was a difference between the recorded data and the perception of the participants on their recall reports of activity levels in the post-study questionnaire.
Table 3

Workplace activity change for Intervention and Control groups

\begin{tabular}{|c|c|c|c|}
\hline & Negative & Positive & Zero \\
\hline \multicolumn{4}{|l|}{ Sit } \\
\hline Control group & 2 & 2 & 7 \\
\hline $\begin{array}{l}\text { Intervention group } \\
p \text {-value }=0.169\end{array}$ & 6 & $\mathbf{0}$ & 6 \\
\hline \multicolumn{4}{|l|}{ Stand } \\
\hline Control group & 1 & 1 & 9 \\
\hline $\begin{array}{l}\text { Intervention group } \\
{ }^{*} \text { indicates } p \text {-value }=0.027\end{array}$ & 0 & $7^{*}$ & 5 \\
\hline \multicolumn{4}{|l|}{ Walk } \\
\hline Control group & 2 & 0 & 9 \\
\hline $\begin{array}{l}\text { Intervention group } \\
* \text { indicates } p \text {-value }=0.0197 .\end{array}$ & 1 & $6^{*}$ & 5 \\
\hline
\end{tabular}

Table 4

Leisure activity change for Intervention and Control groups

\begin{tabular}{lccc}
\hline Leisure Activity & Negative & Positive & Zero \\
\hline Control group & 2 & 1 & 8 \\
Intervention group & $\mathbf{1}$ & $\mathbf{7}^{*}$ & $\mathbf{4}$ \\
\hline
\end{tabular}

*indicates $p$-value $=0.033$.

The Control group reported higher rates of sitting than the Intervention group recording either 'always' $(40 \%)$ or 'often' $(60 \%)$ and this was supported by their recall reports.

A Fisher's Exact Test for frequencies for recalled workplace activity over the previous month is presented in (Table 3).

For all three activities of sitting, standing and walking at work over the previous month there were more positive changes for the Intervention group indicating increased activity. It was more significant for standing $(p=0.027)$ and walking $(p=0.0197)$ than for sitting $(p=0.169)$.

In contrast there were no significant changes in reports of feeling tired after work $(p=1.00)$ for either of the two groups. One Intervention subject reported a positive on the Fisher's Exact Test, three reported a reduction of tiredness and eight subjects reported no change. Seven of the Control subjects reported no change and four subjects reported a reduction in tiredness. This implies that having an EAHD did not result in increased subjective tiredness, despite reports of increased activity at work for the Intervention (EAHD) group.

\subsection{Leisure activity}

There is evidence to suggest that having an EAHD was associated with increased activity during leisure $(p=0.039)$. The Fischer's Exact Test (Table 4) 
indicates that the perceived changes from Pre to Post trial are significantly different for the Control and Intervention groups with only one person of the Intervention group reporting a perceived reduction in leisure activity.

There was gender bias with females in the Intervention group more likely to report being active than males in the Intervention group $(p=0.02)$. Similarly males in the Intervention group were more likely to report being active than males in the Control group. However, when further examined with the Fisher's Exact Test there was not enough evidence $(p=0.422)$ to suggest the changes had a relationship with gender. In this study females reported a lesser change in leisure activity, while males reported an overall perception of increase of activity irrespective of being in the Intervention or Control groups.

\section{Discussion}

This study was a field based trial of office workers using EAHDs in a natural office setting. Despite the small sample size the findings of the study supported the hypothesis that the introduction of EAHDs as a specific intervention is associated with increased physical activity and reduced sitting time in the workplace. The results also indicated an increase in leisure time activity for the Intervention group.

Pedometer step count levels demonstrate an increase in activity by the Intervention group as they stepped more than the Control group in the period of the allocation of EAHD. This shows the introduction of EAHD had an effect on workplace activity as measured by step counts. The average work day step counts in the present study were fewer (intervention $4287 \pm 2379$; control $3988 \pm 3042$ ) than a previous New Zealand study which collected data on workplace step counts using pedometers [56], where office workers recorded $5380 \pm 2730$ steps during a working day. However, the step count was higher than recorded in an Australian study of white collar university employees [57] (3616 1519 steps/working day) and higher than the one day baseline recordings by Tobin et al. [36] (2435 SD1026). The authors [56, 57] cautioned that the pedometer may have acted as a physical activity promoter for their studies, both of which were over three consecutive working days. As the present study lasted for over four months any physical activity promotion effect is likely to have been low. Further, the Control group did not exhibit an overall change in their step counts over the study period.

Pedometers were used as they were easily accessible, were unobtrusive and the participants had previous experience in using pedometers at the workplace. They were used in the present study in an effort to obtain objective data and to complement the subjective self-report PAD data, since Thorp et al. [58] cautioned against reliance on recall measures for physical activity. Pedometers do not capture low level activity which is possible with more sophisticated devices such as accelerometers and inclinometers [59]. Other studies on AHDs and sitting have used self-reports for activity [5, 11, 25-27, 37, 60-62] in conjunction with objective measures. Not all studies reported units of time used in activity diaries but those that did varied from 5 minute intervals [63] to end of day recall of hours and minutes [60, 62]. Time units of 15 minutes were used in this study to encourage compliance and minimise interference with productivity. For their study on reliability on time use surveys Rhodes et al. [64] questioned the validity of self-reports but Ellegast et al. [5], in a study of assessment of physical activity at work, found a significant correlation between self-reports and objectively measured activity. In the present study the PAD was completed during the designated measurement day, along with the pedometer readings, and did not rely on recall of prior activity. In contrast the preand post-questionnaires about physical activity were subject to recall bias, but the participant's answers reflected their overall activity.

Analysis of the fortnightly PAD showed the EAHD Intervention group sat for half as long as the FSHD Control group. (Intervention 35\% of work time; Control $77 \%$ of work time.) Thus, the allocation of an EAHD was strongly associated with reduced sitting times. Other studies [22, 34-36] obtained similar results, where sitting times were also halved for an intervention group in comparison with a control group in which sitting times remained unchanged. The recorded sitting times of the Control group (77\%) in the present study were in agreement with the findings of baseline studies of activity in the workplace [12, 26, 36].

Time spent standing still was negligible for the Control group (less than $1 \%$ ), whilst it increased to $16 \%$ of work time for the Intervention AHD group. Healy et al. [34] reported standing times doubled for the intervention group who were allocated desk mounted workstations and showed a slight reduction for their control group. Increased physical activity 
for the Intervention group was similar to the study by Healy et al. [34] which found light physical activity (i.e. standing and walking) for the intervention group was double that for the control group. However Tobin et al. [36] found no significant differences for time spent stepping or number of steps taken after four weeks of use of a sit stand workstation. There were interesting variations between the baseline readings for the Intervention group against the Control group. The Intervention group recorded less sitting during the pre-allocation of the desks. All participants had already been allocated pedometers during this time, however the anticipation of the allocation of an AHD may have encouraged the Intervention group. There was not any evidence of demotivation by the Control group, many of whom had seen the trial as an opportunity to trial an AHD. The length of the study was deliberate to reduce the Hawthorne effect and as the Intervention Group showed a consistent increase in activity over a prolonged period it seems unlikely there was any Hawthorne effect. There was a gender difference in the Intervention group of daily selfreported activity with males reporting sitting less and standing still more than females. Intervention females were almost twice more likely to move less than $1.5 \mathrm{~m}$ than Intervention males. This gender activity difference is difficult to explain. The Control group did not have any significant gender differences for activity levels. Although there was an almost equal mix of males and females in the trial, the total number of participants was small, so it was unlikely that significant gender effects would be found. In contrast, Straker et al. [39], in a one-shift study of 131 call centre employees (female $n=91$ ), reported that a reduction in sitting was most notable in females. Van Dommelen [12] noted there was a gender difference with females spending more time in light intensity physical activity and had less sedentary time than the males in her studies. Other studies have not had a significant gender mix so there is little evidence to support a gender difference in changes of activity or reduced sitting. Any future field based studies should aim to examine gender differences more thoroughly as this may provide for targeted workplace activity interventions.

According to the fortnightly physical activity diary the Intervention group sat less, walked more and stood more at work than the Control group. However, the recall questionnaire from the post questionnaire indicated Intervention participants recalled more sitting than their fortnightly physical activity diary records. The Control group showed more correlation in their recall as there was minimal change in their activity levels as measured by both PAD and step counts. The Intervention group may have a lack of self-awareness of their activity levels. This may have been due to the intermittent recording of daily activity as it was only one day per fortnight and the use of fifteen minute intervals used to record their predominant activity in that time period. There would have been more variation of activity than the time period allowed for reporting. The lack of detail in activity recording would have been countered with the use of more sophisticated measuring devices such as accelerometers or observational studies, both of which could influence activity. Future field based research should also consider including the use of an objective desk-linked measurement device to record desk level changes which will give further objective information about the transitions from sitting to standing levels.

No other environmental or behavioural interventions were employed to promote physical activity or encourage the participant's use of EAHDs. Several studies [65-67] have noted a significant decrease in sitting times associated with ergonomics awareness. In contrast, although Straker et al. [39] found modest decreases in sitting time associated with AHDs, no significant differences were found with 'ergonomics awareness training', analogous to education/information provision. Several studies [22, 25, 26, 33, 35, 36 , used desk mounted workstations in the workplace and showed substantial reductions in sitting time at work. However some of these studies involved non-randomised participants who were employed in health related roles and were not considered to be representative of the general population as they had prior knowledge about the evidence on the effects of prolonged sitting. Dutta's subjects were reminded weekly to stand for more than half their work day [35]. Participants in this study were unaware of current research (measured by two pre- and post-study open ended health awareness questions). Thus, for this study changes in activity could be considered to be primarily associated with having an EAHD.

Tiredness after work was reported in self-reports pre- and post-trial. Despite significant increases in perceived physical activity at work, three Intervention participants reported feeling less tired while eight reported no change. Four of the Control group reported feeling less tired and the rest reported no change. Other studies have used various constructs for tiredness and fatigue. Hasegawa et al. [68] has questions on drowsiness, motivation and muscle fatigue and reported a reduction when subjects were 
allowed to move. Pronk et al. [25] reported $87 \%$ of subjects felt more energised with the allocation of the sit-stand workstation however, the effect was not sustainable and returned to baseline with the removal of the workstations. Husemann et al. [69] noted there was a dual cost of standing and working in a five-day laboratory study and expected an increase in reported tiredness but there was no significant change. A longer field based study [5] reported participants felt more awake with the use of standing workstations. Dutta reported there was no compensatory increase in sitting during non-work hours despite increased standing during work hours [35]. The allocation of EAHD did not have an impact on reports of tiredness indicating there is not a negative effect of increased physical activity at work.

A self-evaluation question on leisure activity levels was asked in the pre- and post-trial questionnaire. There was a statistically significant increase in perceived leisure activity for the Intervention group who also had increased levels of workplace physical activity during the trial. There was no reported increase in leisure activity for the Control group who had no increase in workplace physical work activity during the trial. In a study on a workplace physical activity intervention [51] there was a minor increase in physical activity for the intervention group at 12 month follow up. A recent study on adjustable height workstations [33] reported a reduction in television viewing time (as an indication of leisure sitting) for the intervention group and no change for the control group. Further objective research with larger sample size is needed to examine if increases in workplace activity have a positive effect on non-work activity levels. A direction for future research could be identifying the individual personality factors which influence the activity levels at the workplace. This would have implications for encouraging activity for less active, and therefore, more at risk individuals.

This study has several strengths. It was conducted in a natural office setting with participants who were located through the workplace in both single or open plan offices and not clustered therefore not providing group peer pressure on activity levels. Another strength was that participants were allowed to select their own postures whilst working. This differs from previous studies in which participants were directed when to sit or stand and for specific durations [35, $66,69,70]$. The only incentive for the participants to participate in the study was a chance to try a different desk from their traditional sitting desk. In the present study, the only intervention was an environmental modification - no behavioural modifications were used. This was a conscious choice in study design of this trial. It is already known that educational training (i.e. a behavioural modification) about the health benefits of AHDs can produce enhance usage [28, 34, 67] Despite the EAHD being the only intervention in the present study, the results of this randomised controlled field trial support subsequent studies to show that an environmental modification, without a contemporaneous behavioural modification, can cause a significant change in workplace activity.

Furthermore, the intervention was randomly assigned, controlled and carried out over 16 weeks. Most previously reported field trials have been over 4 weeks and have used desk mounted workstations, not desks [22, 26-28, 32-36]. There was a good representation of males in the study as some previous studies have been gender biased which makes comparisons difficult.

A limitation of the present study was the small sample size, but this is common in realistic field studies. It is difficult to do robust statistical analysis of small sample sizes, however the results obtained in this study reflected other study findings. Other limitations were the lack of sensitive objective and subjective measurements. Like us, Gilson et al. [71] also reported a disparity in objective and subjective reports of standing desk use. Although pedometers have been shown to give an indication of activity, they, like accelerometers, are not sensitive enough to distinguish between standing still and sitting which is an important difference in occupational sitting research. For this reason, the present study did not attempt to distinguish between standing still and sitting. Selfreports were not sensitive enough to capture possible incidental changes in movement despite the use of manageable time units. One of the advantages of the present study was that it was conducted in a real workplace. However this also acted as a constraint because work took priority and the collection of data was limited so as not to interfere with productivity. Although questions on leisure time and tiredness were adapted from validated questionnaires, they were not assessed for reliability and validity, so our findings concerning leisure time should be explored more fully in a separate study.

\section{Conclusions}

This randomised controlled field pilot study has shown that the introduction of EAHDs in the 
workplace is associated with an increase of physical activity levels and reduced sitting times for office based workers. This statistically significant increase in light activity was a result of a passive intervention of environmental modification of introducing EAHDs and did not require behavioural modification by the participants. Participants using the EAHDs in this study also reported an increase in their leisure time activity levels. By using an EAHD at work there is a positive effect on worker's overall health by increasing light physical activity and reducing sitting, and there is evidence that the increase in work activity has a positive impact on leisure time activity.

\section{Conflict of interest}

There are no conflicts of interest to declare.

\section{References}

[1] Franco G, Fusetti L. Bernardino Ramazzini's early observations of the link between musculoskeletal disorders and ergonomic factors. Appl Ergon. 2004;35(1):67-70. doi: 10.1016/j.apergo.2003.08.001

[2] Callaghan JP, McGill SM. Low back joint loading and kinematics during standing and unsupported sitting. Ergonomics. 2001;44(3):280-94. doi: $10.1080 / 00140130010008110$

[3] Waxman A. WHO global strategy on diet, physical activity and health. Food Nutr Bull. 2004;25(3).

[4] Levine JA, Miller JM. The energy expenditure of using a "walk-and-work" desk for office workers with obesity. Br J of Sports Med. 2007;41(9):558-61. doi: 10.1136/bjsm.2006.032755

[5] Ellegast R, Weber B, Mahlberg R. Method inventory for assessment of physical activity at VDU workplaces. Work. 2012;41:2355-9. doi: 10.3233/WOR-2012-0464-2355

[6] Matthews CE, Chen KY, Freedson PS, Buchowski MS, Beech BM, Pate RR, et al. Amount of time spent in sedentary behaviors in the United States, 2003-2004. Am J Epidemiol. 2008;167(7):875-81. doi: 10.1093/aje/kwm390

[7] Owen N, Bauman A, Brown W. Too much sitting: A Novel and important predictor of chronic disease risk? Br J of Sports Med. 2009;43(2):81-3. doi: 10.1136/bjsm.2008.055269

[8] Dunstan DW, Howard B, Healy GN, Owen N. Too much sitting-a health hazard. Diabetes Res Clin Pract. 2012;97(3):368-76. doi: 10.1016/j.diabres.2012.05.020

[9] Gilson N, McKenna J, Puig-Ribera A, Brown W, Burton N. The International Universities Walking Project: Employee step counts, sitting times and health status. Int J Workplace Health Manag. 2008;1(3):152-61. doi: 10.1108/17538350810926516

[10] Chau JY, van der Ploeg HP, van Uffelen JGZ, Wong J, Riphagen I, Healy GN, et al. Are workplace interventions to reduce sitting effective? A systematic review. Prev Med. 2010;51(5):352-6. doi: 10.1016/j.ypmed.2010.08.012
[11] Parry S, Straker L. The Contribution of office work to sedentary behaviour associated risk. BMC Public Health. 2013;13(1):296. doi: 10.1186/1471-2458-13-296

[12] van Dommelen P, Coffeng JK, van der Ploeg HP, van der Beek AJ, Boot CRL, Hendricksen IJM. Objectively measured total and occupational sedentary time in three work settings. PLoS ONE. 11(3):e0149951. doi: 10.1371/journal.pone.0149951

[13] Morris JN, Crawford MD. Coronary heart disease and physical activity of work. BMJ. 1958;2(5111):1485.

[14] Brown WJ, Miller YD, Miller R. Sitting time and work patterns as indicators of overweight and obesity in Australian adults. J Obes. 2003;27(11):1340-6. doi: 10.1038/sj.ijo.0802426

[15] Ekblom-Bak E, Hellénius M-L, Ekblom B. Are we facing a new paradigm of inactivity physiology? Br J of Sports Med. 2010;44(12):834-5. doi: 10.1136/bjsm.2009.067702

[16] Owen N, Healy GN, Matthews CE, Dunstan DW. Too much sitting: The Population-Health science of sedentary behavior. Exerc Sport Sci Rev. 2010;38(3):105-13. doi: 10.1097/JES.0b013e3181e373a2

[17] Gilson ND, Burton NW, van Uffelen JGZ, Brown WJ. Occupational sitting time: Employees' perceptions of health risks and intervention strategies. Health Promot J Austr. 2011;22(1):38-43. doi: 10.1071.HE11038

[18] Healy GN, Clark BK, Winkler EAH, Gardiner PA, Brown WJ, Matthews CE. Measurement of adults' sedentary time in population-based studies. Am J Prev Med. 2011;41(2):216-27. doi: 10.1016/j.amepre2011.05.005

[19] Buckley JP, Hedge A, Yates T, Copeland RJ, Loosemore M, Hamer M, et al. The Sedentary office: A Growing case for change towards better health and productivity. Expert statement commissioned by Public Health England and the Active Working Community Interest Company. Br J Sports Med. Online First. 2015. doi: 10.1136/bjsports-2015094618

[20] Barnes J, Behrens TK, Benden ME, Biddle S, Bond D, Brassard P, et al. Letter to the Editor: Standardized use of the terms "sedentary" and "sedentary behaviours". Appl Physiol Nutr Me. 2012;37(3):540-2. doi: 10.1139/H2012024

[21] Hamilton MT, Healy GN, Dunstan DW, Zderic TW, Owen $\mathrm{N}$. Too little exercise and too much sitting: Inactivity physiology and the need for new recommendations on sedentary behavior. Curr Cardiovasc Risk Rep. 2008;2(4):292-8. doi: 10.1007/s12170-008-0054-8

[22] Graves LEF, Murphy RC, Shepherd SO, Cabot J, Hopkins ND. Evaluation of sit-stand workstations in an office setting: A Randomised controlled trial. BMC Public Health. 2015;15:1145. doi: 10.1186/s12889-015-2469-8

[23] Davis KG, Kotowski SE, Sharma B, Herrmann D, Krishnan AP. Combating the effects of sedentary work: Postural variability reduces musculoskeletal discomfort. In: Proceedings of the Human Factors and Ergonomics Society 53rd Annual Meeting. 2009;53(14); SAGE Publications. pp. 884-6. doi: $10.1177 / 154193120905301406$

[24] Hutcheson AK, Piazza AJ, Knowlden AP. Work site based environmental interventions to reduce sedentary behaviour: A Systematic review. Am J Health Promot. 2018;32(1):3247. doi: 10.1177/0890117116674681

[25] Pronk NP, Katz AS, Lowry M, Payfer JR. Reducing occupational sitting time and improving worker health: The Take-a-Stand Project, 2011. Prev Chronic Dis. 2012:9110323. doi: $10.5888 /$ pcd9.110323 
[26] Alkhajah TA, Reeves MM, Eakin EG, Winkler EAH, Owen N, Healy GN. Sit-Stand workstations: A Pilot intervention to reduce office sitting time. Am J Prev Med. 2012;43(3):298-303. doi: 10.1016/j.amepre.2012.05.027

[27] Grunseit AC, Chau JYY, van der Ploeg HP, Bauman A. "Thinking on your feet": A Qualitative evaluation of sitstand desks in an Australian workplace. BMC Public Health. 2013;13(1):365. doi: 10.1186/1471-2458-13-365

[28] Neuhaus M, Healy GN, Dunstan DW, Owen N, Eakin EG. Workplace sitting and height-adjustable workstations: A Randomized controlled trial. Am J Prev Med. 2014;46(1):30-40. doi: 10.1016/j.amepre.2013.09.009

[29] Thorp AA, Healy GN, Winkler E, Clark BK, Gardiner PA, Owen N, et al. Prolonged sedentary time and physical activity in workplace and non-work contexts: A Cross-Sectional study of office, customer service and call centre employees. Int J Behavioral Nutr Phys Act. 2012;9(1):128-128. doi: 10.1186/1479-5868-9-128

[30] Stephens SK, Winkler EAH, Trost SG, Dunstan DW, Eakin EG, Chastin SFM, et al. Intervening to reduce workplace sitting time: How and when do changes to sitting time occur? Br J Sports Med. 2014;48:1037-42. doi: 10.1136/bjsports2014-093524

[31] Dunstan DW, Wiesner G, Eakin EG, Neuhaus M, Owen $\mathrm{N}$, LaMontagne AD, et al. Reducing office workers' sitting time: Rationale and study design for the Stand Up Victoria cluster randomized trial. BMC Public Health. 2013;13(1):1057. doi: 10.1186/1471-2458-13-1057

[32] Chau JY, Daley M, Srinivasan A, Dunn S, Bauman AE, van der Ploeg HP. Desk-based workers' perspectives on using sit-stand workstations: A Qualitative analysis of the Stand@ Work study. BMC Public Health. 2014a;14(1):752. doi: 10.1186/1471-2458-14-752

[33] Chau JY, Daley M, Dunn S, Srinivasen A, Do A, Bauman AE, et al. The effectiveness of sit-stand workstations for changing office workers' sitting time: Results from the Stand@ Work randomized controlled trial pilot. Int J Behav Nutr Phys Act. 2014b;11:127. doi: 10.1186/s12966-0140127-7

[34] Healy GN, Eakin EG, LaMontagne AD, Owen N, Winkler EAH, Wiesner $G$, et al. Reducing sitting time in office workers: Short-term efficacy of a multicomponent intervention. Prev Med. 2013;57(1):43-8. doi: 10.1016/j.ypmed.2013.04.004

[35] Dutta N, Koepp GA, Stovitz SD, Levine JA, Pereira MA. Using sit-stand workstations to decrease sedentary time in office workers: A Randomised crossover trial. Int J Environ Res Public Health. 2014;11:6653-65. doi: 10.3390/ijpreh110706653

[36] Tobin R, Leavy J, Jancey J. Uprising: An Examination of sit-stand workstations, mental health and work ability in sedentary office workers, in Western Australia. Work. 2016;55:359-71. doi: 10.3233/WOR-162410

[37] Hedge A, Ray EJ. Effects of an electronic heightadjustable worksurface on computer worker musculoskeletal discomfort and productivity. In: Proceedings of the Human Factors and Ergonomics Society Annual Meeting. 2004;48(8): SAGE Publications. pp. 1091 - 5 doi: 10.1177/154193120404800803

[38] Wilks S, Mortimer M, Nylén P. The Introduction of sit-stand worktables; aspects of attitudes, compliance and satisfaction. Appl Ergon. 2006;37(3):359-65. doi: 10.1016/j.apergo.2005.06.007

[39] Straker L, Abbott RA, Heiden M, Mathiassen SE, Toomingas A. Sit-stand desks in call centres:
Associations of use and ergonomics awareness with sedentary behavior. Appl Ergon. 2013;44(4):517-22. doi: 10.1016/j.apergo.2012.11.001

[40] Karakolis T, Callaghan JP. The Impact of sit-stand office workstations on worker discomfort and productivity: A Review. Appl Ergon. 2014;45(3):799-806. doi: 10.1016/j.apergo.2013.10.001

[41] Nerhood HL, Thompson SW. Adjustable sit-stand workstations in the office. In: Proceedings of the Human Factors and Ergonomics Society Annual Meeting. 1994;38(10): SAGE Publications. pp. 668-72 doi: 10.1177/154193129403801028

[42] Dainoff MJ. The Effect of ergonomic worktools on productivity in today's automated workstation design. Center for Ergonomic Research. Miami University: Oxford, Ohio, 2002.

[43] Ryan CG, Dall PM, Granat MH, Grant PM. Sitting patterns at work: Objective measurement of adherence to current recommendations. Ergonomics. 2011;54(6):531-8. doi: 10.1080/00140139.2011.570458

[44] Messing K, Stock S, Tissot F. The Importance of not standing too long. Archives Environ Occup Health. 2013;68(2):128-9. doi: 10.1080/19338244.2013.764714

[45] Straker L, Mathiassen SE. Increased physical work loads in modern work-a necessity for better health and performance? Ergonomics. 2009;52(10):1215-25. doi: $10.1080 / 00140130903039101$

[46] Tissot F, Messing K, Stock S. Studying the relationship between low back pain and working postures among those who stand and those who sit most of the working day. Ergonomics. 2009;52(11):1402-18. doi: 10.1080/00140130903141204

[47] Cooley D, Pedersen S. A Pilot study of increasing nonpurposeful movement breaks at work as a means of reducing prolonged sitting. J Environ Public Health. 2013. doi: 10.1155/2013/128376

[48] Chau JY, van der Ploeg HP, Merom D, Chey T, Bauman AE. Cross-sectional associations between occupational and leisure-time sitting, physical activity and obesity in working adults. Prev Med. 2012;54(3):195-200. doi: 10.1016/j.ypmed.2011.12.020

[49] McCrady SK, Levine JA. Sedentariness at work: How much do we really sit? Obesity. 2009;17(11):2103-5. doi: 10.1038/oby.2009.117

[50] Jans MP, Proper KI, Hildebrandt VH. Sedentary behavior in Dutch workers: Differences between occupations and business sectors. Am J Prev Med. 2007;33(6):450-4. doi: 10.1016/j.amepre.2007.07.033

[51] Aittasalo M, Miilunpalo S, Suni J. The Effectiveness of physical activity counseling in a work-site setting: A Randomized, controlled trial. Patient Educ Couns. 2004;55(2):193-202. doi: 10.1016/j.pec.2003.09.003

[52] Bassett DR, Wyatt HR, Thompson H, Peters JC, Hill JO. Pedometer-Measured physical activity and health behaviours in U.S. adults. Med Sci Sports Exerc. 2010;42(10):1819-25 doi: 10.1249/MSS.0b013e181dc2e54

[53] Laperrière E, Messing K, Couture V, Stock S. Validation of questions on working posture among those who stand most of the work day. Int J Ind Ergon. 2005;35:371-8 doi: 10.1016/j.ergon.2004.10.006

[54] Baecke JAH, Burema J, Frijters JER. A short questionnaire for the measurement of habitual physical activity in epidemiological studies. Am J Clin Nutr. 1982;36(5):936-42.

[55] Florindo AA, Latorre MRDO. Validation and reliability of the Baecke questionnaire for the evaluation 
of habitual physical activity in adult men. Rev Bras Med Esporte. 2003;9(3):129-35. doi: 10.1590/S151786922003000300002

[56] Schofield G, Badlands H, Oliver M. Objectively-measured physical activity in New Zealand workers. J Sci Med Sport. 2005;8(2):143-51. doi: 10.1016/S1440-2440(05)80005-2

[57] Steele R, Mummery K. Occupational physical activity across occupational categories. J Sci Med Sport. 2003;6(4):398-407. doi: 10.1016/S1440-2440(03)80266-9

[58] Thorp AA, Owen N, Neuhaus M, Dunstan DW. Sedentary behaviors and subsequent health outcomes in adults: A Systematic review of longitudinal studies, 1996-2011. Am J Prev Med. 2011;41(2):207-15. doi: 10.1016/j.amepre.2011.05.004

[59] Melanson EL, Knoll JR, Bell ML, Donahoo WT, Hill JO, Nysse LJ, et al. Commercially available pedometers: Considerations for accurate step counting. Prev Med. 2004;39(2):361-8. doi: 10.1016/j.ypmed.2004.01.032

[60] Miller R, Brown W. Steps and sitting in a working population. Int J Behav Med. 2004;11(4):219-24. doi: 10.1207/s15327558ijbm1104_5

[61] Vink P, Konijn I, Jongejan B, Berger M. Varying the office work posture between standing, half-standing and sitting results in less discomfort. In: Karsh B-T, Ed. Ergonomics and Health Aspects of Work with Computers. Berlin Heidelberg: Springer, 2009, pp. 115-20.

[62] Clark BK, Thorp AA, Winkler EAH, Gardiner PA, Healy $\mathrm{GN}$, Owen $\mathrm{N}$, et al. Validity of self-reported measures of workplace sitting time and breaks in sitting time. Med Sci Sports Exerc. 2011;43(10):1907-12. doi: 10.1249/MSS.0b013e31821820a2

[63] Van der Ploeg H, Mermon D, Chau J, Bittman, M, Trost S, Bauman A. Advances in population surveillance for physical activity and sedentary behaviour: Reliability and validity of time use surveys. Am J Epidemiol. 2010;172:1199-206 doi: 10.1093/aje/kwq265
[64] Rhodes RE, Mark RS, Temmel CP. Adult sedentary behavior: A Systematic review. Am J Prev Med. 2012;42(3):e3-e28. doi: 10.1016/j.amepre.2011.10.020

[65] Laestadius JG, Ye J, Cai X, Ross S, Dimberg L, Klekner M. The proactive approach-is it worthwhile? A prospective controlled ergonomic intervention study in office workers. J Occup Environ Med. 2009;51(10):1116-24. doi: 10.1097/JOM.0b013e3181bae19d

[66] Robertson MM, Ciriello VM, Garabet AM. Office ergonomics training and a sit-stand workstation: Effects on musculoskeletal and visual symptoms and performance of office workers. Appl Ergon. 2013;44(1):73-85. doi: 10.1016/j.apergo.2012.05.001

[67] Karol S, Robertson MM. Implications of sit-stand and active workstations to counteract the adverse effects of sedentary work: A Comprehensive review. Work. 2015;52:255-67. doi: 10.3233/WOR-152168

[68] Hasegawa T, Inoue K, Tsutsue O, Kumashiro M. Effects of a sit-stand schedule on a light repetitive task. Int J Ind Ergon. 2001;28(3):219-24. doi: 10.1016/S0169-8141(01)00035-X

[69] Husemann B, von Mach CY, Borsotto D, Zepf KI, Scharnbacher J. Comparisons of musculoskeletal complaints and data entry between a sitting and a sit-stand workstation paradigm. Hum Factors. 2009;51(3):310-20. doi: $10.1177 / 0018720809338173$

[70] Ebara T, Kubo T, Inoue T, Murasaki G, Takeyama H, Sato T, et al. Effects of adjustable sit-stand VDT workstations on workers' musculoskeletal discomfort, alertness and performance. Ind Health. 2008;46(5):497-505. doi: 10.2486/indhealth.46.497

[71] Gilson ND, Suppini A, Ryde GC, Brown HE, Brown WJ. Does the use of standing 'hot'desks change sedentary work time in an open plan office? Prev Med. 2012;54(1):65-7. doi: 10.1016/j.ypmed.2011.10.012 